\title{
Uncovering the hidden diversity of Paleogene sponge fauna of the East European Platform through reassessment of the record of isolated spicules
}

\author{
Magdalena Łukowiak, Andrzej Pisera, and Tetiana Stefanska \\ Acta Palaeontologica Polonica 64 (4), 2019: 871-895 doi:https://doi.org/10.4202/app.00612.2019
}

Despite being reported from various localities and stratigraphic intervals, knowledge of the siliceous sponges from the Cenozoic of Eastern Europe remains surprisingly limited. Studies assessing their diversity are almost exclusively in Russian and rather hard to obtain. The most comprehensive elaboration of the sponge spicules from the Paleogene of the East European Platform was published in 2003 and deals with material from Ukraine, Russia, Belarus, and Lithuania. However, the classification in that paper is purely artificial and extremely difficult to interpret according to modern biological criteria. A reassessment of this material is carried out, with the aim of revising all morphotypes of spicules, and identifying them to the lowest possible taxonomic level. Results suggest that the assemblage is much more diverse than previously thought, including members of 24 demosponge families (class Demospongiae), one homoscleromorph (class Homoscleromorpha), and at least one hexactinellid (class Hexactinellida). Our improved understanding of the diversity of Paleogene sponge fauna of the East European Platform will have implications for the interpretation of the past and future ecological and paleobiogeographic studies.

Key words: Demospongiae, Homoscleromorpha, Hexactinellida, spicules, Ukraine, Russia, Eocene.

Magdalena Łukowiak [mlukowiak@twarda.pan.pl] and Andrzej Pisera [apis@ twarda.pan.pl ], Institute of Paleobiology, Polish Academy of Science, Twarda 51/55 00-818 Warszawa, Poland. Tetiana Stefanska [t.stefanska@ukr.net], Institute of Geological Sciences, National Academy of Science of Ukraine, O. Gonchar St. 55-B 02054 Kiev, Ukraine.

This is an open-access article distributed under the terms of the Creative Commons Attribution License (for details please see creativecommons.org), which permits unrestricted use, distribution, and reproduction in any medium, provided the original author and source are credited. 
FoF Full text $(2,484.4 \mathrm{kB})$ 